\title{
TRANSIENT MODELING OF AC MACHINES CONSIDERING SECOND ORDER EFFECTS
}

\author{
Olga Korolova, Juan de la Torre Cubillo, Bernd Ponick \\ Leibniz Universität Hanover, Institute for Drive Systems and Power Electronics
}

Abstract. In this paper, the transient simulation of AC machines considering spatial field harmonics and current displacement in rotor bars is examined. The first point of discussion is the sufficient order of the equivalent circuit of the current displacement model for its accurate co-simulation with the higher spatial field harmonics. In the second place, the problem of inversion of the inductance matrix considering the flux linkage through higher spatial harmonics is studied.

Keywords: AC motors, transient simulation, spatial field harmonics, current displacement

\section{MODELOWANIE STANÓW PRZEJŚCIOWYCH MASZYN PRĄDU PRZEMIENNEGO Z UWZGLĘDNIENIEM EFEKTÓW DRUGIEGO RZĘDU}

\begin{abstract}
Streszczenie. $W$ artykule przeanalizowano symulację stanów przejściowych maszyn prąu przemiennego z uwzględnieniem harmonicznych pola przestrzennego $i$ przesunięcia prądu $w$ prętach wirnika. Po pierwsze przeanalizowano jaki jest wystarczający rząd modelu równoważnego obwodu przesunięcia pradu dla jego dokładnej symulacji wraz z wyższymi harmonicznymi pola przestrzennego. Po drugie, badany jest problem inwersji macierzy induktancji z uwzględnieniem sprzęzenia strumienia przez wyższe harmoniczne przestrzenne.
\end{abstract}

Słowa kluczowe: maszyny prądu przemiennego, modelowanie stanów przejściowych, wyższe harmoniczne, przestrzenne przesunięcie prądu

\section{Introduction}

The work reported in this paper was performed as a part of the interdisciplinary project AMSES whose purpose is the detailed simulation of transient interactions in electromechanical energy systems consisting of mains, power electronics, electrical machines and their driven equipment or driving turbines. For the simulation, the so-called modified component connecting modeling (mCCM) [6] is used which gives an opportunity to connect subsystems describing different physical processes and construction elements using a special software interface. The advantages of this method are widely described in [7], whereas the main focus of this concept is the easy accessibility of all inner processes of the simulated system. Another task of the mCCM is to enable the order reduction of the simulated system in order to reduce the computational effort. As an intermediate step towards solving this problem, this paper focuses on the problems of simulation of different types of AC machines with $\mathrm{mCCM}$ for their further integration into the joint electromechanical system. In order to pursue this task, it is necessary to prepare the AC machine model for the analysis and simulation with $\mathrm{mCCM}$, e.g. to bring the ordinary differential equations (ODEs) of an $\mathrm{AC}$ machine into a form appropriate for mCCM. This paper focuses on the study of some aspects of mathematical modeling of AC machines as well as on their numerical solution considering parasitic effects such as higher spatial field harmonics and current displacement in the rotor bars. The general approaches of the model development which base on [1-3] and [8] are described in Sec. 1. Since one of the purposes of the interdisciplinary project AMSES is to create subsystem models which are easily scalable to different modeling depths and accuracies, the AC machine models should also provide the opportunity of such scaling. Thus, the question of a reasonable order of the current displacement model for the chosen number of higher harmonics for their co-simulation will be discussed in Sec. 2. Numerical aspects of the transient simulation of AC machines with higher spatial harmonic effects only as well as the problem of adapting this model to the mCCM structure will be described in Sec. 3. The saturation is neglected and the mechanical part is simulated as one-mass system in the analysis performed.

\section{Modeling of the higher spatial harmonics and the current displacement effects}

The system of ODEs describing the electromagnetic subsystem of each AC machine with three phases in the stator, which is able to consider the higher spatial harmonic effects such as torque pulsations or additional losses as well as the current displacement effect, is formulated in the general form as

$$
\mathbf{u}=\frac{d(\mathbf{L}(\varphi) \mathbf{i})}{d t}+\mathbf{R i}=\mathbf{L}(\varphi) \frac{d \mathbf{i}}{d t}+\frac{\partial \mathbf{L}(\varphi)}{\partial \varphi} \frac{d \varphi}{d t} \mathbf{i}+\mathbf{R i}
$$

with the state space vector

and the input vector

$$
\mathbf{i}=\left[i_{S 1}, i_{S 2}, i_{S 3}, i_{R 1}, i_{R 2}, i_{R 3} \ldots\right]^{\mathrm{T}}
$$

$$
\mathbf{u}=\left[u_{S 1}, u_{S 2}, u_{S 3}, u_{R 1}, u_{R 2}, u_{R 3} \ldots\right]^{\mathrm{T}}
$$

where $\varphi$ is the electrical rotor angle, $\mathbf{i}$ is the vector of currents (indexes $\mathrm{S}$ and $\mathrm{R}$ stand for stator and rotor, respectively), $\mathbf{u}$ is the vector of the applied voltages and $\mathbf{L}(\varphi)$ and $\mathbf{R}$ are the inductance and resistance matrices, respectively. The vector of currents $\mathbf{i}$ can be expressed in different coordinate frameworks, e.g. in the frequently used two-axis rotating frame $(d q)$ [4]. However, for the modeling of higher harmonics, the stationary coordinate framework (123) is the most convenient approach. As for most numerical solvers, the differential equations need to be written in an explicit form, i.e. $d \mathbf{y} / d t=f(\mathbf{y})$ The ODEs (1) are transformed into this form as

$$
\frac{d \mathbf{i}}{d t}=-\mathbf{L}^{-1}(\varphi)\left(\frac{\partial \mathbf{L}(\varphi)}{\partial \varphi} \frac{d \varphi}{d t}+\mathbf{R}\right) \mathbf{i}+\mathbf{L}^{-1}(\varphi) \mathbf{u}
$$

The inductance matrix $\mathbf{L}(\varphi)$, considering the higher spatial harmonics produced by the magnetic asymmetries of stator and rotor and by the nonsinusoidal distribution of the $\mathrm{mmf}$ in the stator and rotor windings, shows the dependency of all its elements on the angle $\varphi$

$$
\mathbf{L}(\varphi)=\left[\begin{array}{cccccc}
L_{S 1, S 1}(\varphi) & L_{S 1, S 2}(\varphi) & \ldots & L_{S 1, R 1}(\varphi) & L_{S 1, R 2}(\varphi) & \ldots \\
L_{S 2, S 1}(\varphi) & L_{S 2, S 2}(\varphi) & \ldots & L_{S 2, R 1}(\varphi) & L_{S 2, R 2}(\varphi) & \ldots \\
\ldots & \ldots & \ldots & \ldots & \ldots & \ldots \\
L_{R 1, S 1}(\varphi) & L_{R 1, S 2}(\varphi) & \ldots & L_{R 1, R 1}(\varphi) & L_{R 1, R 2}(\varphi) & \ldots \\
L_{R 2, S 1}(\varphi) & L_{R 2, S 2}(\varphi) & \ldots & L_{R 2, R 1}(\varphi) & L_{R 2, R 2}(\varphi) & \ldots \\
\ldots & \ldots & \ldots & \ldots & \ldots & \ldots
\end{array}\right](5)
$$

with the inductance of the flux linkage between the phases $i$ and $j$ through the spatial harmonic $k$

$$
L_{i, j}(\varphi)=\sum_{k} \hat{L}_{i, j, k} \cos \left(\varphi \cdot v_{k}+\alpha_{i, j, k}\right),
$$

where $v_{\mathrm{k}}$ is the order of the $\mathrm{k}$-th spatial harmonic and $\alpha_{\mathrm{i}, \mathrm{j}, \mathrm{k}}$ is the respective phase angle.

The equations (1)-(5) take different forms dependent on the rotor type of the considered AC machine. Thus, in case of induction machines with squirrel cage rotor or in case of synchronous machines with damper cage, solving of ODEs for each loop of the rotor cage is necessary for the correct simulation which leads to a 
significant increase of the computational effort. In case of machines carrying rotor windings with slip rings such as windings of wound rotor induction machines, real measurable currents of the rotor phases are chosen as the state space variables in (2), so that the state space vector takes the form $\mathbf{i}=\left[i_{\mathrm{S} 1}, i_{\mathrm{S} 2}, i_{\mathrm{S} 3}, i_{\mathrm{R} 1}, i_{\mathrm{R} 2}, i_{\mathrm{R} 3}\right]^{\mathrm{T}}$. The analysis performed in Sec. 3 is limited to this type of machines.

The results of the transient simulation according to (1)-(5) for a doubly-fed induction machine with the rated data listed in Tab. 1 synchronized by a DC voltage applied between two rotor phases at a speed of $n=1500 \mathrm{rpm}$ with the following stationary no-load operation is shown in Fig. 1. The influence of the higher spatial harmonics can be seen both, in the rotor current and in the stator current, as oscillations with the frequencies $250 \mathrm{~Hz}$ and $350 \mathrm{~Hz}$ in the stator current and $300 \mathrm{~Hz}$ in the rotor current. This corresponds to the expected response of the stator current to the field spatial harmonics $(-5 p, 7 p)$ produced by rotor mmf distribution and to the expected response of the rotor current to the field harmonics $(-5 p, 7 p)$ produced by stator $\mathrm{mmf}$ distribution according to the spatial harmonic theory [3]. The oscillations of the rotor current are fairly low because the fundamental of the stator current is low due to (almost) no-load.

Table 1. Rating and dimensions of the test machine (doubly-fed induction machine)

\begin{tabular}{|l|l|}
\hline \multicolumn{1}{|c|}{ Parameter } & \multicolumn{1}{c|}{ Value } \\
\hline power & $2080 \mathrm{~kW}$ \\
\hline pole pairs & 2 \\
\hline stator frequency & $50 \mathrm{~Hz}$ \\
\hline speed & $1780 \mathrm{rpm}$ \\
\hline voltage & $690 \mathrm{~V}(\mathrm{Y})$ \\
\hline current & $1780 \mathrm{~A}$ \\
\hline moment of inertia & $88 \mathrm{kgm}^{2}$ \\
\hline stator outer diameter & $890 \mathrm{~mm}$ \\
\hline
\end{tabular}

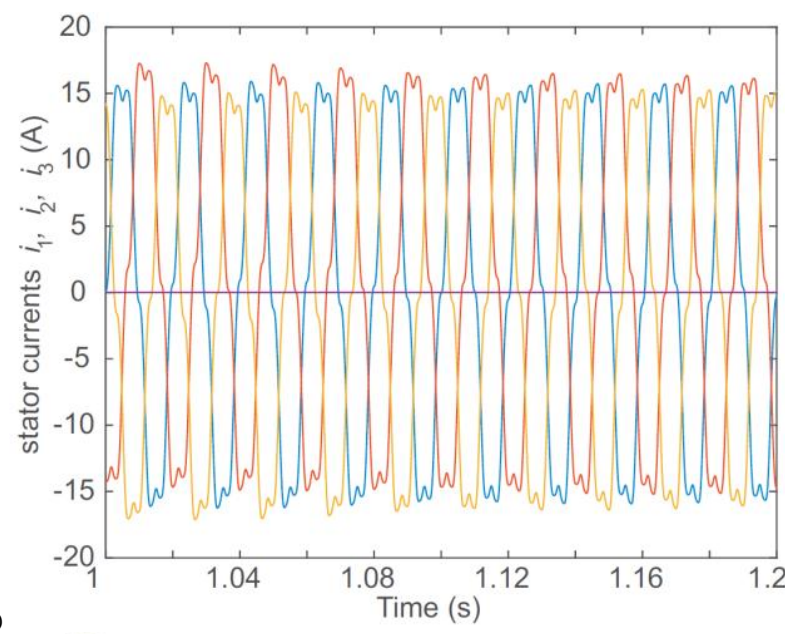

a)

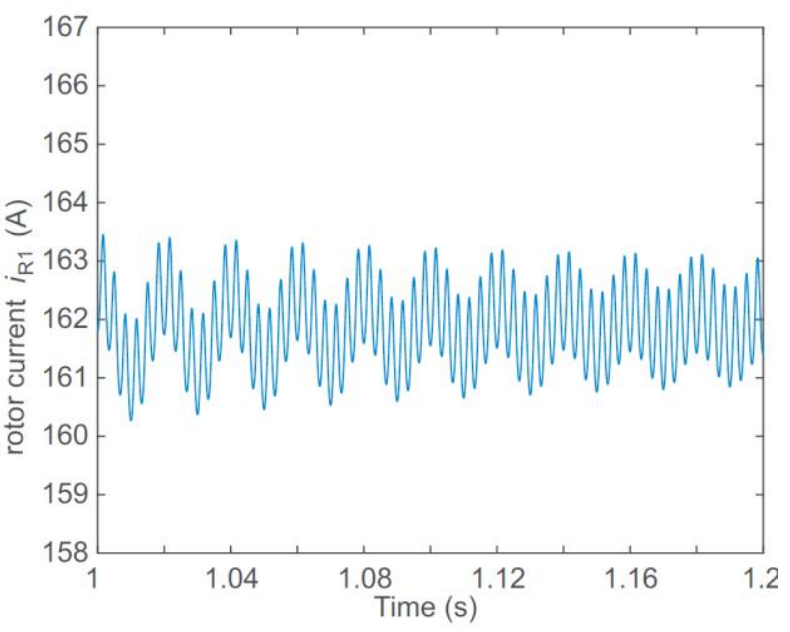

The effect of current displacement can be most frequently observed in cage induction machines with deep bars or with double squirrel cage rotors and to some extent in damper cages of electrically excited synchronous motors in case they are designed for the direct start-up from the mains. Thus, the simulation approach concerning current displacement as well as the analysis performed in Sec. 2 are suitable for the aforementioned types of motors. The combined model for the co-simulation of the higher harmonic effect and the rotor current displacement effect is applicable directly to the wound rotor induction machines and to doubly-fed induction machines as well as to cage induction machines and synchronous machines with damper cages after extending the model with additional loop equations for the rotor cage.

In order to model the current displacement effect in the rotor bars, the equivalent circuit was used based on the discretization of the partial differential equations [3] by fragmentation of the bar geometry similarly to the approach described in [5]. The assumption is made that all rotor bars have the same geometry and that the distribution of the current density over the slot height is the same for all slots. The electromagnetic model of each rotor phase is extended with the equivalent circuit as shown in Fig. 2.

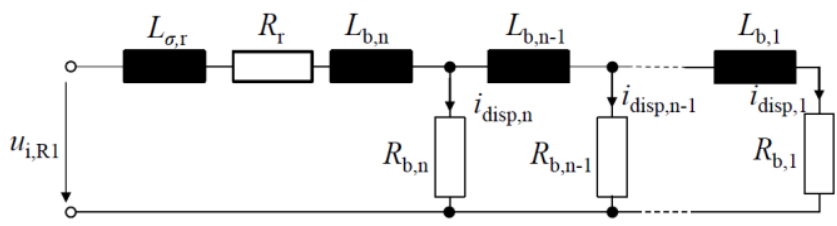

Fig. 2. Equivalent circuit for modeling of the current displacement effect in the rotor bars

The system of ODEs, describing the transient processes in this equivalent circuit for a particular rotor phase R1, if induced voltage $u_{\mathrm{i}}$ is applied as input signal, can be formulated in the matrix form as

$$
\begin{gathered}
\frac{d \mathbf{i}_{R 1, \text { disp }}}{d t}=-\mathbf{L}_{R 1, \text { disp }}^{-1} \mathbf{R}_{R 1, \text { disp }} \mathbf{i}_{R 1, \text { disp }}+\mathbf{L}_{R 1, \text { disp }}^{-1} \mathbf{B}_{R 1, \text { disp }} u_{i, R 1}, \\
i_{R 1, \text { disp }}=\mathbf{C}_{R 1, \text { disp }} \mathbf{i}_{R 1, \text { disp }},
\end{gathered}
$$

with

$$
\begin{gathered}
\mathbf{i}_{R 1, \text { disp }}=\left[i_{R 1, \text { disp }, 1}, i_{R 1, \text { disp }, 2}, \ldots\right]^{\mathrm{T}}, \\
\mathbf{L}_{R 1, \text { disp }}=\left[\begin{array}{ccccc}
L_{b, 1} & 0 & \ldots & \ldots & 0 \\
L_{b, 2} & L_{b, 2} & 0 & \ldots & 0 \\
\vdots & \vdots & \ddots & \ddots & \vdots \\
L_{b, n}+L_{\sigma, r} & L_{b, n}+L_{\sigma, r} & \ldots & \ldots & L_{b, n}+L_{\sigma, r}
\end{array}\right] \\
\mathbf{R}_{R 1, \text { disp }}=[0 \ldots, 1]^{\mathrm{T}}, \quad \mathbf{C}_{R 1, \text { disp }}=[1,1, . .1] \\
{\left[\begin{array}{cccccc}
R_{b, 1} & -R_{b, 2} & 0 & 0 & \ldots & 0 \\
0 & R_{b, 2} & -R_{b, 3} & 0 & \ldots & \vdots \\
\vdots & \vdots & \ddots & \ddots & R_{b, n-1} & -R_{b, n} \\
R_{r} & R_{r} & R_{r} & R_{r} & R_{r} & R_{b, n}+R_{r}
\end{array}\right]}
\end{gathered}
$$

where $R_{\mathrm{b}, \mathrm{i}}$ and $L_{\mathrm{b}, \mathrm{i}}$ are the resistance and inductance of each fictive parallel conductor inside the rotor bar, respectively, which depend on the slot geometry and on the number of the branches of the equivalent circuit chosen, $L_{\sigma, \mathrm{r}}$ and $R_{\mathrm{r}}$ are the leakage reactance and resistance, respectively, which are free from current displacement (e.g. a segment of the short circuit ring) and the currents $i_{\mathrm{R} 1 \text {,disp,k }}$ correspond to the currents $i_{\text {disp,k }}$ from Fig. 2 . In order to integrate the current displacement effect ODEs into the model (1)-(5), the components $\mathbf{i}, \mathbf{u}, \mathbf{L}(\varphi)$ and $\mathbf{R}$ are modified as

$$
\mathbf{L}=\left[\begin{array}{cccc}
{\left[\begin{array}{cccc}
L_{S 1, S 1} & L_{S 1, S 2} & \ldots & L_{S 1, f d} \\
L_{S 2, S 1} & L_{S 2, S 2} & \ldots & L_{S 2, f d} \\
\ldots & \ldots & \ldots & \ldots \\
L_{f d, S 1} & L_{f d, S 2} & \ldots & L_{f d, f d}
\end{array}\right] \mathbf{L}_{\text {non-disp,disp }}} \\
& \mathbf{L}_{\text {disp,non-disp }} & & \mathbf{L}_{\text {disp }}
\end{array}\right]
$$

Fig. 1. Fragment of the simulation results for the synchronization process and following stationary no-load operation for the doubly-fed induction machine under consideration of higher spatial harmonics: a) stator currents $i_{S I}, i_{S 2}$ and $i_{S 3}, b$ ) current of one rotor phase $i_{R I}$ 


$$
\begin{aligned}
& \mathbf{L}_{n o n-d i s p, d i s p}=\left[\begin{array}{ccc}
L_{S 1, R 1} & L_{S 1, R 2} & \ldots \\
L_{S 2, R 1} & L_{S 2, R 2} & \ldots \\
\ldots & \ldots & \ldots \\
L_{f d, R 1} & L_{f d, R 2} & \ldots
\end{array}\right] \cdot\left[\begin{array}{cccc}
\mathbf{C}_{R 1, d i s p} & 0 & 0 & \ldots \\
0 & \mathbf{C}_{R 2, d i s p} & 0 & \ldots \\
\ldots & \ldots & \ldots & \ldots
\end{array}\right](14) \\
& \mathbf{L}_{\text {disp,non-disp }}=\left[\begin{array}{cccc}
\mathbf{B}_{R 1, d i s p} & 0 & 0 & \ldots \\
0 & \mathbf{B}_{R 2, \text { disp }} & 0 & \ldots \\
\ldots & \ldots & \ldots & \ldots
\end{array}\right] . \\
& {\left[\begin{array}{cccc}
L_{R 1, S 1} & L_{R 1, S 2} & \ldots & L_{R 1, f d} \\
L_{R 2, S 1} & L_{R 2, S 2} & \ldots & L_{R 2, f d} \\
\ldots & \ldots & \ldots & . .
\end{array}\right]} \\
& \mathbf{L}_{\text {disp }}=\left[\begin{array}{cccc}
\mathbf{L}_{R 1, d i s p} & 0 & \ldots & 0 \\
0 & \mathbf{L}_{R 2, d i s p} & \ldots & 0 \\
\ldots & \ldots & \ldots & . .
\end{array}\right]
\end{aligned}
$$

where $\mathbf{L}_{\text {disp,non-disp }}, \mathbf{L}_{\text {non-disp,disp }}$ are the inductance matrices coupling the phases S1, S2... (and the field winding fd in case of electrically excited synchronous machines) and the phases R1, R2... In this paper, the coupling between the rotor bars through the leakage field is neglected but can be easily considered by adding the respective leakage mutual inductances to the matrix $\mathbf{L}_{\text {disp }}$ from (16), whereas the self-inductance of the rotor windings through the main flux should be always considered by adding the respective term to each element of the lower line of $\mathbf{L}_{\text {disp. }}$. The graphics of the transient simulation obtained using the described model of current displacement for the test machine for its asynchronous start-up without higher spatial harmonic effects simulated with $n=3$ parallel branches in the equivalent circuit of each rotor phase are shown in Fig. 3. As can be observed from the branch currents $\mathbf{i}_{\text {disp, } \mathrm{k}}$ which correspond to the current densities inside the rotor bar starting at its bottom for $k=1$, the current displacement effect is strong at the beginning of the start-up and disappears when reaching synchronous speed as it is expected.
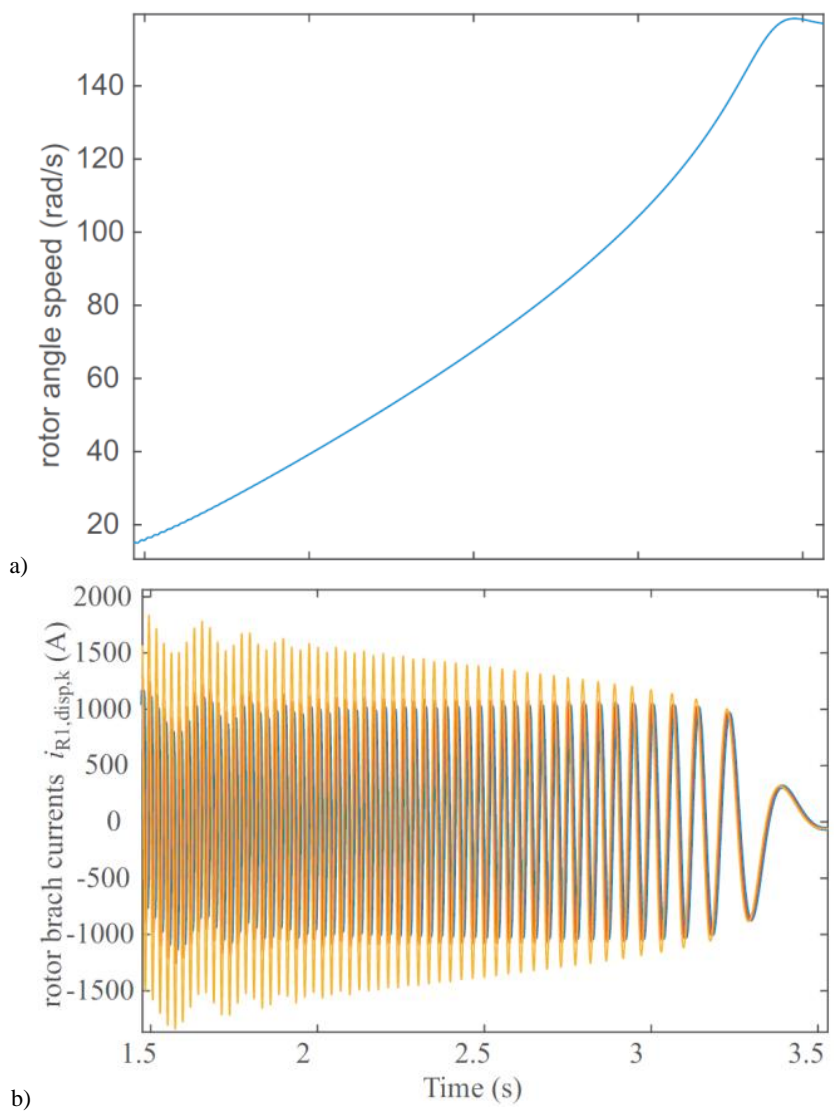

Fig. 3. Results of the simulation of the asynchronous start-up for the test machine under consideration of the current displacement effect in rotor bars: a) rotor speed, b) branch currents in the equivalent circuit for one rotor bar

\section{Scaling of the current displacement model for its co-simulation with higher spatial harmonics}

As shown in [8], the sufficient number of parallel branches of the equivalent circuit of the rotor (Fig. 2) for an accurate transient simulation is $n=4$. However, this estimation is relevant for the simulation considering only the spatial fundamental. By introducing the higher spatial harmonics into the model, the voltage induced in the rotor winding in case of $f_{1}=50 \mathrm{~Hz}$ and slip $s=0$ contains the frequencies

$$
f_{v}=f_{1} \cdot\left(\frac{\omega_{v}}{\omega_{1}}-(1-s) \cdot \frac{v}{p}\right)= \pm 300, \pm 600, \pm 900, \ldots H z
$$

where $\omega_{v} / \omega_{1}=1$ for all spatial harmonics produced by the stator winding. These frequencies lead to a much stronger current displacement, so that the equivalent circuit with $n=4$ elements is not supposed to be accurate enough. The study of the number of branches of the equivalent circuit necessary for the correct simulation for different orders of the spatial harmonics is shown in this section.

As a sufficient criterion of the modeling accuracy, the current displacement factor $k_{\mathrm{r}}$ can be taken as it is shown in Fig. 4. Thus, the current density distribution $\underline{S}$ in one rectangular bar with the height $h=25 \mathrm{~mm}$ and the width $b=5 \mathrm{~mm}$ for the constant frequency of the induced voltage $f=600 \mathrm{~Hz}$ was first calculated analytically according to [3]

$$
\underline{S}=\frac{j \cdot 2 \pi f \mu_{0} \kappa}{\left(1+j b \alpha \cdot\left(e^{(1+j) \beta}-e^{-(1+j) \beta}\right)\right)} \cdot\left(e^{(1+j) \alpha x}+e^{-(1+j) \alpha x}\right) \cdot \underline{i},
$$

where $\alpha$ and $\beta$ are the factors calculated from the slot geometry [3] and $\kappa$ is the electrical conductivity. The stationary simulations for the same slot geometry and frequencies were performed with (7)-(16), and the branch currents $i_{\mathrm{R} 1 \text {,disp, } \mathrm{k}}$ are compared to $|\underline{S}|$ from (18) in Fig. 4. The functions show better correspondence when a higher order of the current displacement model is used. In this case, the factors $k_{\mathrm{r}, \text { an }}$ and $k_{\mathrm{r} \text {,num }}$, which represent the overall current displacement factor $k_{\mathrm{r}}$ obtained analytically and numerically, show approximately the same value.

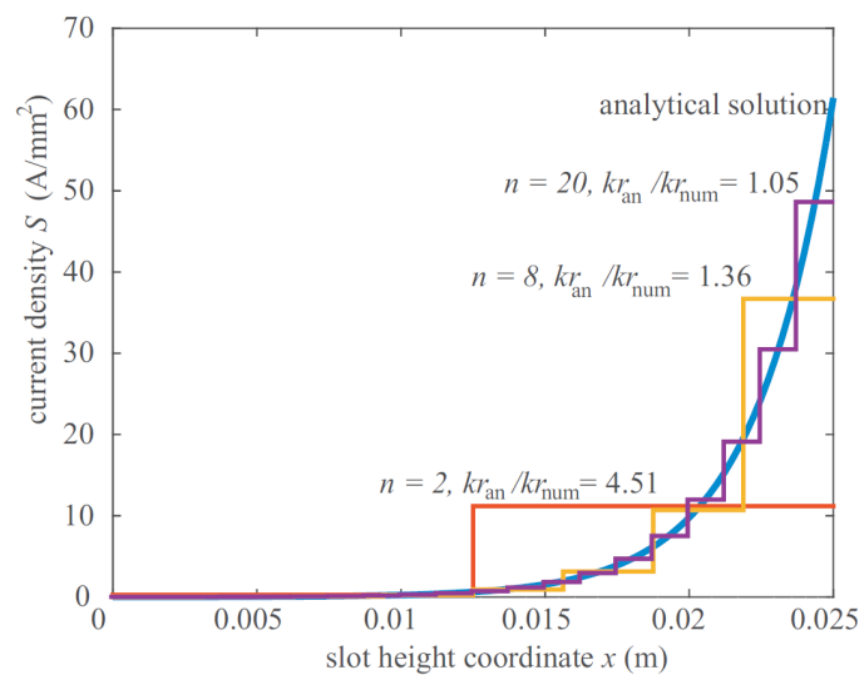

Fig. 4. Current density distribution $|\underline{S}|$ in one rotor bar

The closed-form analytical expression of the current displacement factor for one rotor bar is available for the rectangular slot as [3]

$$
k_{r, r e c t}=\beta \cdot \frac{\sinh 2 \beta+\sin 2 \beta}{\cosh 2 \beta-\cos \beta} .
$$

The results of this calculation are shown in Fig. 5 for the same slot geometry as in Fig. 4. Along with the frequency of the induced voltage $f$, the orders of the spatial harmonics $n$ producing these frequencies at synchronous speed are shown. The current displacement factor $k_{\mathrm{r}, \mathrm{num}}$ was calculated using the results of the numerical simulation according to (7)-(16) for different numbers of branches $n$ as 


$$
k_{r, \text { num }}=\frac{\operatorname{Re}\left(\frac{\underline{U}_{i}}{\sum \underline{I}_{k}}\right)}{R(f=0)},
$$

The numerical solution $k_{\mathrm{r}, \text { num }}$ converges to the ideal solution $k_{\mathrm{r}, \text { an }}$ for large values of $n$. Thus, approximately 25 parallel branches are required for the correct simulation (accuracy of $10 \%$ in $k_{\mathrm{r}}$ ) of the rotor current response to the voltage induced by harmonics $(-23 p, 25 p)$. For the lower harmonic orders $(-5 p, 7 p)$, approximately 10 branches are sufficient to obtain the same accuracy. The same analysis was performed for a round bar with the diameter $h=10 \mathrm{~mm}$. The results are shown in Fig. 6. Generalizing the results obtained, the following criterion for the choice of the appropriate order of the equivalent circuit $n$ is proposed. The rough estimation of the current displacement factor $k_{\mathrm{r}, \mathrm{an}}$ must be performed first using analytical formulations such as (19) for the rotor induction frequency (17) of the highest simulated harmonic $v_{\max }$. The order $\mathrm{n}$ should be chosen as $n \approx 2 \cdot k_{\mathrm{r} \text {,an }}$ for an accuracy of approximately $10 \%$ in $k_{\mathrm{r}}$.

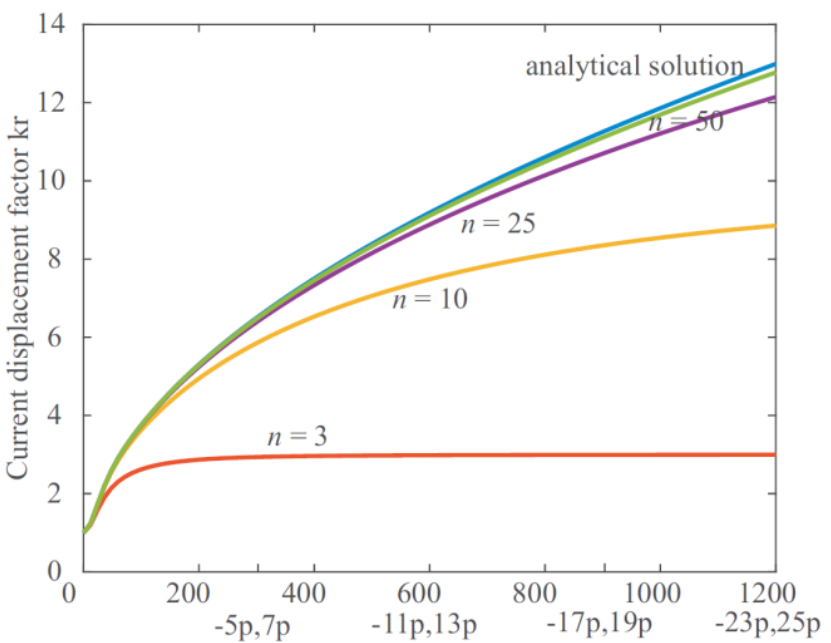

frequency $f(\mathrm{~Hz})$ and spatial harmonic order $v$

Fig. 5. Current displacement factor $k_{r}$ dependent on the number of equivalent circuit order $n$ for a rectangular bar

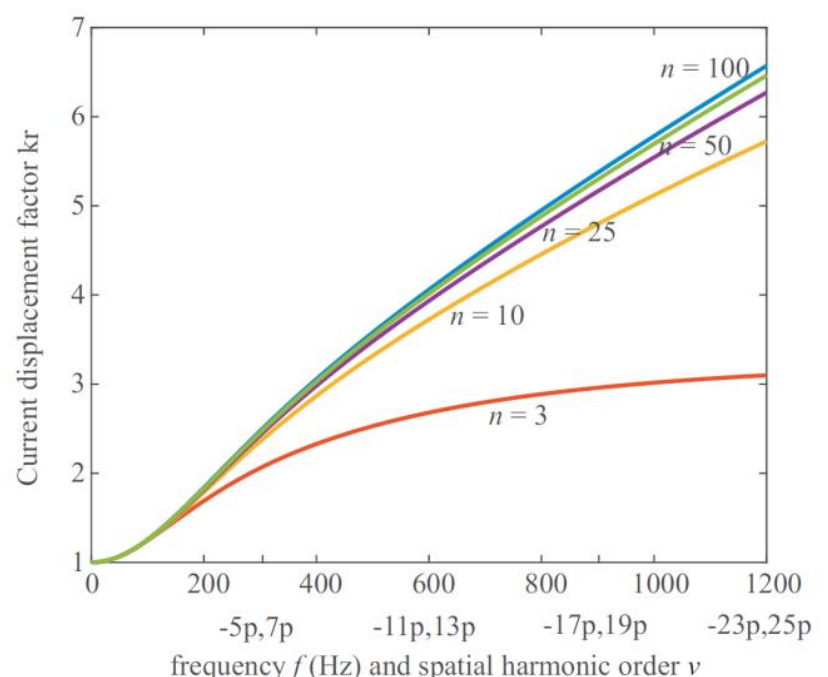

Fig. 6. Current displacement factor $k_{r}$ dependent on the number of equivalent circuit order $n$ for a round bar

\section{Numerical aspects of the higher harmonics simulation}

For an efficient analysis of a general AC machine with the modified component connecting modeling (mCCM), different parasitic effects should be split into subsystems for studying their interactions and possibilities of a further order reduction. Trans- forming the ODEs (1) with current displacement effect into this required form does not show any difficulties and was described in [7]. In order to use all advantages of mCCM for the higher harmonics, the structure of the transient model considering higher spatial harmonics, as shown in Fig. 7 (a), should be achieved. The main features of this structure are: firstly, the function $\mathbf{f}\left(\mathbf{u}, \mathbf{u}_{\mathrm{v} 0}, \ldots \mathbf{u}_{\mathrm{vk}}\right)$ does not depend on the rotor position $\varphi$ and, secondly, each function $\mathbf{g}\left(\mathbf{i}, v_{\mathrm{i}} \varphi, \mathbf{u}\right)$ contains only one higher harmonic order $v_{\mathrm{i}}$. The direct transformation of (1) into the required form is not possible because of the product of matrices $\mathbf{L}^{-1}(\varphi)$ and $\mathbf{R}$, since each element of the inverse matrix $\mathbf{L}^{-1}(\varphi)$ contains a fraction of the sum of products of harmonic functions with different values of $n$ in the argument.
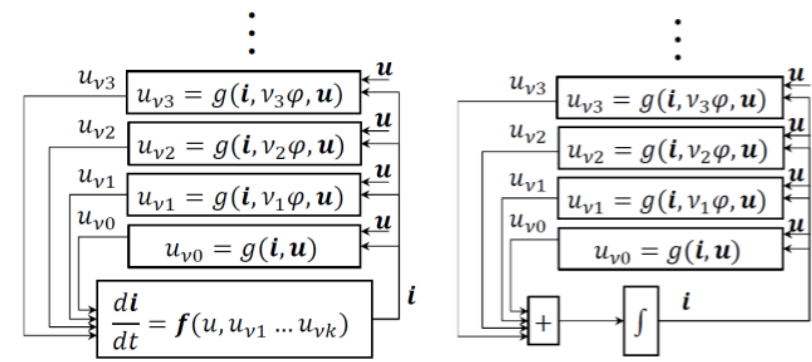

Fig. 7. MCCM structure required for the model of higher harmonics: a) general mCCM structure, $b$ ) desired mCCM structure (decoupled harmonics subsystems)

In order to transform (4) into this form, a software tool for the analytical inversion of matrix $\mathbf{L}(\varphi)$ was developed. Using the general matrix inversion rules

$$
\mathbf{L}^{-1}(\varphi)=\frac{1}{\operatorname{det}(\mathbf{L}(\varphi))} \cdot \operatorname{adj}(\mathbf{L}(\varphi))
$$

where $\operatorname{adj}(\mathbf{L}(\varphi))$ is the adjugate of matrix $\mathbf{L}(\varphi)$, and subsequent trigonometrical simplifications, the inverse matrix $\mathbf{L}^{-1}(\varphi)$ is transformed into

$$
\mathbf{L}^{-1}(\varphi)=\left[\begin{array}{ccc}
\frac{\sum_{i} L_{n u m, 1,1, i} \cos \left(v_{i} \varphi+\alpha_{1,1, i}\right)}{\sum_{j} L_{d e n, j} \cos \left(v_{j} \varphi+\beta_{j}\right)} & \frac{\sum_{i} L_{n u m, 1, i} \cos \left(v_{i} \varphi+\alpha_{1,2, i}\right)}{\sum_{j} L_{d e n, j} \cos \left(v_{j} \varphi+\beta_{j}\right)} & \ldots \\
\frac{\sum_{i} L_{n u m, 2,1, i} \cos \left(v_{i} \varphi+\alpha_{2,1, i}\right)}{\sum_{j} L_{d e n, j} \cos \left(v_{j} \varphi+\beta_{j}\right)} & \frac{\sum_{i} L_{n u m, 2,2, i} \cos \left(v_{i} \varphi+\alpha_{2,2, i}\right)}{\sum_{j} L_{d e n, j} \cos \left(v_{j} \varphi+\beta_{j}\right)} & \ldots \\
\ldots & \ldots & \ldots \\
\ldots & \ldots \\
=\frac{\sum_{i} \mathbf{L}_{n u m, i} \cos \left(v_{i} \varphi+\boldsymbol{\alpha}_{i}\right)}{\sum_{j} L_{d e n, j} \cos \left(v_{i} \varphi+\beta_{i}\right)} &
\end{array}\right]=
$$

Each element of $\mathbf{L}^{-1}(\varphi)$ contains a finite sum of harmonic functions in numerator and denominator. Thus, the part functions $\mathbf{g}\left(\mathbf{i}, v_{\mathrm{i}} \varphi, \mathbf{u}\right)$ for the terms $\mathbf{L}^{-1}(\varphi)(-\mathbf{R i}+\mathbf{u})$ from (4) can be presented as

$$
\begin{gathered}
\mathbf{u}_{n u m, i}=\mathbf{g}_{n u m, i}\left(\mathbf{u}, \mathbf{i}, v_{i} \varphi\right)=\mathbf{L}_{n u m, i} \cos \left(v_{i} \varphi+\boldsymbol{\alpha}_{i}\right)(-\mathbf{R i}+\mathbf{u}) \\
u_{\text {den }, j}=g_{\text {den }, j}\left(v_{j} \varphi\right)=L_{\text {den }, j} \cos \left(v_{j} \varphi+\beta_{j}\right)
\end{gathered}
$$

The function $\mathbf{f}\left(\mathbf{u}, \mathbf{u}_{v 0}, \mathbf{u}_{v 1} \ldots\right)$ can be expressed as

$$
\mathbf{f}\left(\mathbf{u}, \mathbf{u}_{v 0}, \mathbf{u}_{v 1} \ldots\right)=\frac{\mathbf{u}_{n u m, v 0}+\mathbf{u}_{n u m, v 1}+\ldots}{u_{d e n, v 1}+u_{d e n, v 2}+\ldots},
$$

whereas it does not depend explicitly on the rotor position $\varphi$, so that the required form from Fig. 7 (a) is accomplished. The same transformation is applied to the product of the matrices $\mathbf{L}^{-1}(\varphi) \cdot \partial \mathbf{L}(\varphi) / \partial \varphi$ in order to obtain the full family of functions $\boldsymbol{g}_{\text {num,i }}$. Furthermore, the question was raised whether the elements of the inverse matrix $\mathbf{L}^{-1}(\varphi)$ are possible to be represented as a sum of harmonic functions as shown in Fig. 7 (b) without division operation in each element through the number of simplifications using the regular predictable structure of all elements of the original inductance matrix $\mathbf{L}(\varphi)$. Such simplification of the model considering first harmonic only is possible due to the mathematical feature that the determinant of the inductance matrix 
$\operatorname{det}(\mathbf{L}(\varphi))=$ const is independent of the value of $\varphi$. After a number of transformations performed, it was found that the form without division, as in (22), cannot be achieved, so that the structure 7(b) can be considered unattainable for a general case. The analysis of the possible simplifications for particular machines is still an object of study. As an alternative approach to the problem, the Fourier transformation method applied directly to all elements of the inverse matrix $\mathbf{L}^{-1}(\varphi)$ was implemented and tested. According to this method, the inverse matrix $\mathbf{L}^{-1}(\varphi)$ is calculated numerically for $\varphi=0 \ldots 2 \pi$ with a large number of steps. The spectral analysis of each element of $\mathbf{L}^{-1}(\varphi)$ is performed with the Fourier transformation for the first $n$ harmonics. After this operation, the inverse matrix $\mathbf{L}^{-1}(\varphi)$ can be split into the sum of matrices

$$
\mathbf{L}^{-1}\left(v_{1} \varphi, v_{2} \varphi, \ldots\right) \approx \mathbf{L}_{0, i n v}+\mathbf{L}_{1, i n v}\left(v_{i n v, 1} \varphi\right)+\mathbf{L}_{2, i n v}\left(v_{i n v, 2} \varphi\right)+\ldots \text { (26) }
$$

in order to estimate the impact of each higher harmonic into the system dynamics separately with $\mathbf{g}_{\mathrm{i}}=\mathbf{L}_{\mathrm{i} \text {,inv }}\left(v_{\mathrm{inv}} \varphi\right)(-\mathbf{R} \mathbf{i}+\mathbf{u})$, as it is shown in Fig. 7 (b). The same transformation is applied to the product of the matrices $\mathbf{L}^{-1}(\varphi) \cdot \partial \mathbf{L}(\varphi) / \partial \varphi$. The model obtained in this way has shown a high sensibility to the accuracy of the Fourier transformation, and its numerical simulation always contains an error due to the truncated terms of the Fourier expansion. The simulation of the stationary operation was performed using this model structure, and the interconnection signals $\mathbf{u}_{\mathrm{i}}=-\mathbf{L}_{\mathrm{i}, \text { inv }} \mathbf{R i}$ are exemplarily shown for orders $v_{\text {inv, } \mathrm{i}}=2 p \ldots 6 p$ in Fig. 8. It can be observed that the harmonics $v_{\text {inv, }}=2 p, 5 p, 6 p \ldots$ in the subsystem components $\mathbf{g}_{2}(2 p \varphi), \mathbf{g}_{5}(5 p \varphi), \mathbf{g}_{6}(6 p \varphi) \ldots$ make the strongest impact in the system dynamics.

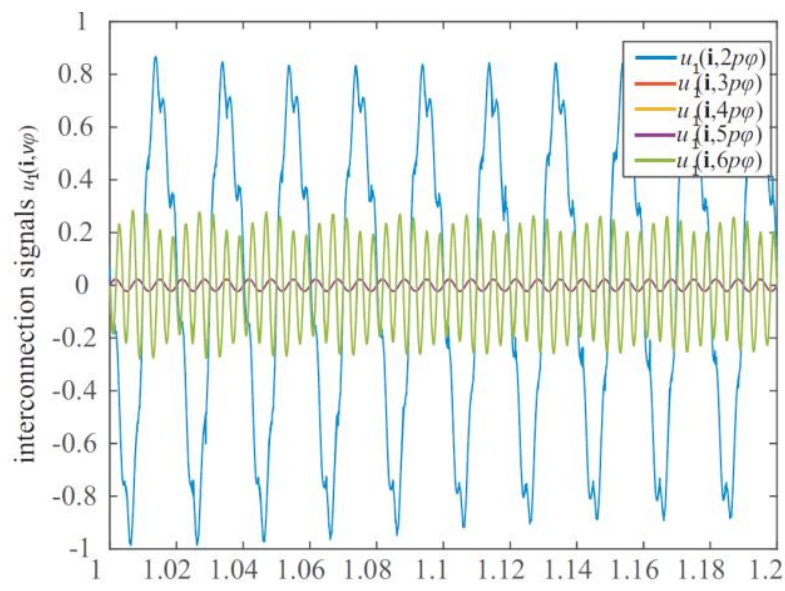

Fig. 8. Example simulation of the higher harmonic effect with the structure required for $\mathrm{mCCM}$ as shown in Fig. 7 (b)

\section{Conclusion}

In this paper, a model for transient simulations of an $\mathrm{AC}$ machine considering higher spatial harmonic effects and current displacement in rotor bars is developed, the differential equations for both effects being scalable to different model accuracies. The analysis of the required modeling accuracy of the current displacement effect for different numbers of spatial field harmonics is performed, and an approach for the simplified estimation is proposed. In order to achieve $10 \%$ accuracy of the current displacement factor for the harmonics of orders $p,(-5 p, 7 p)$ and $(-23 p, 25 p) 3,10$ and 25 elements of the equivalent circuit were necessary for a rectangular bar with the height $h=25 \mathrm{~mm}$ and the width $b=5 \mathrm{~mm}$.

The transformation of the machine model considering higher spatial harmonics into the structure required for an analysis with the component connecting modeling tool was performed. Therefore, the software tool was designed in order to bring all elements of the inverse inductance matrix $\mathbf{L}^{-1}(\varphi)$ by performing analytical inversion into the form $\mathbf{L}^{-1}{ }_{\mathrm{j}, \mathrm{k}}(\varphi)=\left(L_{\mathrm{num}, \mathrm{j}, \mathrm{k}, 1}\left(v_{1} \varphi\right)+L_{\mathrm{num}, \mathrm{j}, \mathrm{k}, 2}\left(v_{2} \varphi\right) \ldots\right)$ $/\left(L_{\mathrm{den}, 1}\left(v_{1} \varphi\right)+L_{\mathrm{den}, 2}\left(v_{2} \varphi\right) \ldots\right)$ in which the interconnection signals of each higher harmonic dynamics could be observed separately. As another approach to this task the approximate inversion using Fourier transformation applied to the inverse inductance matrix $\mathbf{L}^{-1}(\varphi)$ was performed in order to split the impact of higher harmonics on system dynamics into independent parallel branches by achieving the form $\mathbf{L}^{-1}(\varphi) \approx \sum_{\mathrm{i}} \mathbf{L}_{\mathrm{i}, \text { inv }}\left(v_{\mathrm{inv}, \mathrm{i},} \varphi\right)$.

\section{References}

[1] Boldea I., Nasar S.: The Induction Machine Handbook. CRC Press, Boca Raton London New York Washington D.C. 2002.

[2] Gao J., Zhang L., Wang X.: AC Machine Systems. Tsinghua University Press and Springer-Verlag, Berlin 2009

[3] Müller G., Vogt K., Ponick B.: Calculation of Electrical Machines (in German), 6th ed. Wiley-VCH, Weinheim 2012.

[4] Park R.H.: Two Reaction Theory of Synchronous Machines generalized Method of Analysis-Part I. AIEE Transactions 48/1929, 716.

[5] Paszek G.W.: Transient behaviour of the induction machine with high rotor bars. Archiv für Elektrotechnik 63/1981, 77-86.

[6] Popp M., Mathis W., John M., Korolova O., Mertens A., Ponick B.: A Modified CCM Approach for Simulating Hierarchical Interconnected Dynamical Systems. International Symposium on Circuits and Systems, 2017.

[7] Popp M., Mathis W., Korolova O., Ponick B.: A Modified CCM Approach for Simulating Hierarchical Interconnected Dynamical Systems. International Electric Machines and Drives Conference, 2017.

[8] Seinsch H.O.: Transient processes in electrical drives (in German). B.G.Teubner Stuttgart 1991.

\begin{abstract}
M.Sc. Olga Korolova
e-mail: olga.korolova@ial.uni-hannover.de

Olga Korolova received master degree in mechatronics at the Leibniz Universität Hannover in 2013. Since then she is working as a research associate at the Institute for Drive Systems and Power Electronics in Hanover. She focuses on modeling of the transient processes in electrical machines considering parasitic effects. SEW price holder 2015 for developing calculation methods for traction drives
\end{abstract}

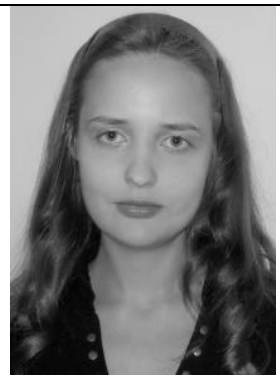

M.Sc. Juan de la Torre Cubillo

e-mail: juan_de_latorre@yahoo.es

Juan de la Torre Cubillo received a Licenciatura (B,Sc. and M.Sc.) in Physics in 2015 from the Universidad Complutense de Madrid. After that he started studying a double degree program "International Mechatronics", at the Leibniz Universität Hannover and St. Petersburg Polytechnic University. Now he is finishing his master thesis on transient processes in motors and working in Ricardo automotive.

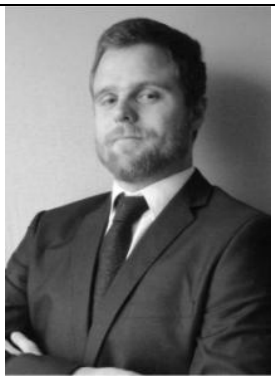

\section{Prof. Bernd Ponick}

e-mail: ponick@ial.uni-hannover.de

Bernd Ponick received Dipl.-Ing. in 1990 and Dr.-Ing. on el. machines in 1994 from the University of Hanover. After working as head of el. design and Technical Director of Siemens Dynamowerk Berlin he became in 2003 full professor at Leibniz Universität Hanover. His main research activities are prediction and simulation methods for el. machines considering parasitic effects and new applications.

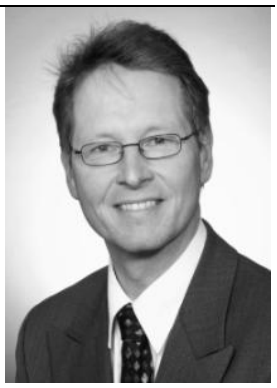

otrzymano/received: 08.12.2017 przyjęto do druku/accepted: 11.05.2018 